\title{
Long term prognosis for babies with neonatal liver disease
}

\author{
J DEUTSCH, A L SMITH, D M DANKS, AND P E CAMPBELL
}

Departments of Gastroenterology, Genetics, and Anatomical Pathology, Royal Children's Hospital; Department of Paediatrics, University of Melbourne; and Birth Defects Research Institute, Melbourne, Australia

SUMmaRY A total of 123 patients with neonatal liver disease without extrahepatic bile duct obstruction or arteriohepatic dysplasia have been studied for six to 18 years. Idiopathic neonatal hepatitis, present in 73 babies, carried a high mortality due to liver failure (18\%), septicaemia $(6 \%)$, and associated defects $(14 \%)$, especially in the first year of life $(25 \%)$. Progression to chronic liver disease in non-familial idiopathic cases occurred in three of 40 reviewed patients. Only 12 of these children were completely healthy, the remainder having other permanent disabilities $(57 \%)$. Four of nine familial cases of idiopathic neonatal hepatitis died in the first 12 months of life as did two of the four reviewed survivors. Progression to chronic liver disease or to death was a continuous process without any interval of recovery in all but one of these patients. Among patients with a presumed infective cause, cytomegalovirus infection caused a particularly benign form of neonatal hepatitis but was a frequent cause of brain damage or other disabilities. Babies who survived other infective liver diseases showed complete healing of the liver damage. Neonatal liver disease associated with $\alpha_{1}$ antitrypsin deficiency progressed to death or chronic liver disease in three of nine patients and was not associated with a paucity of interlobular bile ducts.

Previous studies have shown that it is important to separate patients with neonatal liver disease according to aetiology before determining their prognosis. ${ }^{1-5}$ After excluding specific conditions ${ }^{6}$ most neonatal liver disease is still without a defined cause $;{ }^{124-6}$ some families have more than one affected child. ${ }^{1256}$. Alph $\mathrm{a}_{1}$ antitrypsin deficiency is found in a proportion of babies with neonatal liver disease. ${ }^{1-7}$ It is difficult to know whether this genetic defect is a sufficient explanation for the liver disease ${ }^{8-13}$ or whether it merely acts as a factor predisposing to liver damage by some unknown virus or other agent.

Definition of the prognosis of a condition requires ascertainment of a full range of its clinical forms, thorough investigation to achieve aetiological classification at the time of presentation, ${ }^{14}$ and prolonged follow up. All of these requirements have been met in the prospective study of neonatal liver disease which began in Melbourne in 1962. ${ }^{15} 6$ This report extends the period of observation substantially and describes the outcome in patients followed for six to 18 years.

Groups working in London ${ }^{4}$ and in Paris ${ }^{2}$ have access to larger numbers of patients, but the patterns of referral in these large cities do not give them access to the full range of severity seen in the condition. The follow up period has also been considerably shorter, as in the smaller retrospective study reported from Oslo, ${ }^{3}$ where the pattern of referral is more comparable to that in Melbourne.

\section{Patients and methods}

Case ascertainment has been described in detail elsewhere. ${ }^{56}$ It is thought to be complete for severe cases of neonatal liver disease in Victoria from July 1, 1963 to December 31, 1980, but some mild cases must have escaped detection.

Terminology and classification is a particular problem with neonatal liver disease. Histological examination of the liver was available in all patients by biopsy (generally needle biopsy) or at necropsy. All patients with inflammatory changes in the liver but no mechanical obstruction of the extrahepatic ducts and without arteriohepatic dysplasia ${ }^{15}{ }^{16}$ were 
included-123 babies in total. Initial aetiological studies $^{6}$ identified babies with galactosaemia (five cases), cytomegalovirus hepatitis (21 cases), and hepatitis due to other infective agents (15 cases: syphilis one, toxoplasmosis two, hepatitis B virus two, Coxsackie viruses two, rubella virus three, and adenovirus five). The main group consisted of patients with idiopathic neonatal hepatitis which was sporadic in 64 and familial in nine. Babies with $\alpha_{1}$ antitrypsin deficiency (9) are also considered separately, although this may just represent a specific factor predisposing to neonatal hepatitis.

Regular follow up examinations were achieved as part of clinical care in most cases. Some patients were treated by other paediatricians and reviewed at longer intervals. The patients who died were followed until their death. Eleven patients were lost to follow up despite intensive efforts to trace them. The remaining 77 surviving patients were traced and 67 were re-examined by one of us (JD) who had not known the patients previously. The other 10 patients living outside Melbourne were examined by their own paediatricians. The mean age of the patients at this last follow up was 12 years (range 5 years 11 months to 17 years 4 months). Apart from historical data and a thorough clinical examination, the following biochemical tests were performed in 64 patients: bilirubin, aspartate aminotransferase, and alkaline phosphatase values by routine methods (Department of Biochemistry, Royal Children's Hospital, Melbourne); $\quad \gamma$-glutamyltransferase (Gamma GT Kit, Boehringer); the total concentration of bile acids in the serum by an enzymatic assay $;{ }^{17}$ and the concentration of cholyl-glycine in serum by a commercially available radioimmunoassay (CG-RIA, Abbott) with minor modifications (within batch variation of duplicates $\pm 5 \%$, between batch variation $\pm 10 \%$ ).

Liver disease was regarded as present if hepatomegaly (with or without splenomegaly) was found together with raised serum bile salt values and at least one other biochemical test abnormality. (The upper limits were: bilirubin $15 \mu \mathrm{mol} / \mathrm{l}$, alkaline phosphatase 700 or $800 \mathrm{U} / \mathrm{l}$, according to the age of the patients, aspartate aminotransferase $50 \mathrm{U} / \mathrm{l}, \gamma-$ glutamyltransferase $60 \mathrm{U} / \mathrm{l}$; reference range-mean (SD) - for total bile acids was $8.6(2.9) \mu \mathrm{mol} / \mathrm{l}$ and for cholylglycine was $35.0(22.0) \mu \mathrm{g} / \mathrm{dl}$.) Those patients showing one abnormal result were classified as having slightly abnormal liver function. Where two tests were abnormal (palpable liver and raised bile salts or one abnormal biochemical test result, or raised bile salts with one abnormal biochemical test of liver function) the patients were also classified as having slightly abnormal liver function but this rarely occurred. Liver biopsies were perfomed only if considered necessary for management (two patients).

Intellectual development was estimated from school progress, discussion with the patients, and clinical assessment. Growth retardation was defined by a height below the 3 rd centile in the absence of familial short stature. Informed consent of parents or patients, or both, was obtained for all investigations.

\section{Results}

We were unable to trace 11 patients. One had had a large palpable liver at the age of 14 months and may have developed liver disease. All other patients are known to have survived the disease. Four were lost to follow up during the first year of life and had no signs of liver disease at the date of their last review. One other patient had a palpable liver at the age of 4 years and one patient suffered from hemihypertrophy.

Tables 1 and 2 present most aspects of the outcome with regard to hepatic consequences and other sequelae, some of which are related to associated second diseases. The principal subjects of this analysis are the 73 patients with idiopathic neonatal hepatitis and the nine babies with $\alpha_{1}$ antitrypsin deficiency. The other groups are included only to give a complete picture of the outcome in non-obstructive neonatal liver disease and to emphasise the importance of aetiological classification before speaking of prognosis in individual cases.

Galactosaemia. Galactosaemia is most clearly separate from the other conditions considered and outcome was good from the hepatic point of view. One patient with convulsions who underwent anticonvulsive treatment had raised alkaline phosphatase and $\gamma$-glutamyltransferase values and another had a liver palpable $1 \mathrm{~cm}$ below the costal margin (Table 1) and a borderline alkaline phosphatase value (809 U/1).

Cytomegalovirus hepatitis proved a benign condition in most patients with no early deaths; one late death probably due to liver disease (this child who died from liver failure at the age of 13 months also suffered from tuberculosis of lungs and lymph nodes at the time of death; the liver was free of tuberculosis at necropsy); and no children with established chronic liver disease. Brain damage (Table 2) is the principal serious outcome in this group-severe in four of 16 survivors and mild to moderate in a further three children. The second late death (Table 1) was a retarded boy with microcephalus and 
Table 1 Outcome of babies with. neonatal liver disease

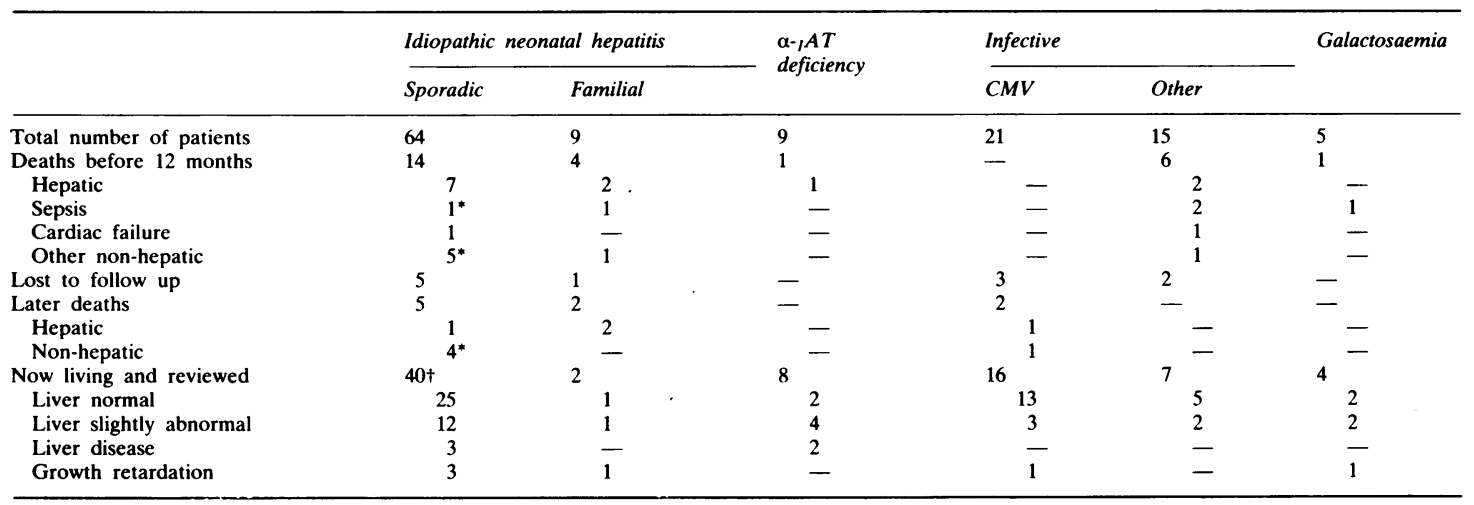

${ }^{*}$ Including 4 patients with severe liver disease at the time of death (see text).

†8 of 16 patients with second diseases survived: Down's syndrome (2), cystic fibrosis (2), generalized fibromatosis (1), Niemann Pick's disease (normal sphingomyelinase) (1), Albright's syndrome (1), chondrodysplasia punctata (1).

$\alpha_{1} \mathrm{AT}=\alpha_{1}$ antitrypsin. $\mathrm{CMV}=$ cytomegalovirus.

Table 2 Other defects present in 77 surviving patients

\begin{tabular}{|c|c|c|c|c|c|c|c|c|}
\hline & \multicolumn{2}{|c|}{ Idiopathic neonatal hepatitis } & \multirow{2}{*}{$\begin{array}{l}\alpha_{1} A T \\
\text { deficiency }\end{array}$} & \multicolumn{2}{|c|}{ Infective } & \multirow[t]{2}{*}{ Galactosaemia } & \multicolumn{2}{|c|}{ At follow up } \\
\hline & Sporadic & Familial & & $C M V$ & Other & & $\begin{array}{l}\text { Liver } \\
\text { disease }\end{array}$ & $\begin{array}{l}\text { Liver slightly } \\
\text { abnormal }\end{array}$ \\
\hline $\begin{array}{l}\text { Total number of infants } \\
\text { (surviving and reviewed) }\end{array}$ & 40 & 2 & 8 & 16 & 7 & 4 & 5 & 24 \\
\hline Intelligence normal & 30 & 2 & 7 & 9 & 4 & 2 & 4 & 15 \\
\hline Slightly retarded & 5 & - & 1 & 3 & 2 & 1 & 1 & 4 \\
\hline Severely retarded & 5 & - & - & 4 & 1 & 1 & - & 5 \\
\hline Convulsions & 5 & - & - & 5 & 5 & 1 & - & 3 \\
\hline Visual defects & 7 & - & - & 1 & 2 & 2 & 1 & 1 \\
\hline Hearing impairment & 2 & - & - & 1 & 4 & 1 & 1 & 1 \\
\hline Speech disturbances & 1 & - & - & 3 & - & - & - & 1 \\
\hline Cerebral palsy & - & - & - & 3 & - & 1 & - & - \\
\hline Microcephalus & - & - & - & 2 & - & - & - & - \\
\hline Congenital heart defects & 1 & 1 & - & - & 4 & - & - & 2 \\
\hline Scoliosis & 3 & - & - & - & - & - & - & 1 \\
\hline $\begin{array}{l}\text { Alive with normal liver and } \\
\text { no disabilities }\end{array}$ & 12 & - & 2 & 5 & 1 & - & & \\
\hline
\end{tabular}

seizures who died of pneumonia at the age of 4 years 6 months.

Other infective causes of hepatitis. These led to an high early fatality rate (toxoplasmosis one death. Coxsackie viruses two deaths, adenovirus two deaths, and rubella virus one death).

Idiopathic neonatal hepatitis. This disease has a high mortality rate (18 or 73 babies) in the first year of life (Table 1), especially in the first three months, due to liver failure (nine deaths), septicaemia (two deaths), and associated defects (seven deaths).
Three patients dying from sepsis or associated defects had severe liver disease at the time of death (jaundice and hepatomegaly combined with splenomegaly, gastrointestinal bleeding or ascites, and laboratory and histologic signs of neonatal hepatitis).

Outcome was determined for 49 of the 55 babies with idiopathic neonatal hepatitis (Table 1) who survived the first year and only seven of these have died subsequently - three of liver failure (one at the age of 4 years 3 months and two at the age of 6 years 2 months), two of septicaemia (at the age of 1 year 11 months and 2 years 11 months, respectively), and 
two because of other defects (one patient at 2 years 6 months due to cot death; another patient due to myocarditis and pneumonitis at the age of 1 year 8 months; this patient had also a biliary cirrhosis). Further deaths may occur among the three children with definite liver disease or the three children with potentially lethal second diseases (Table 1).

Overall, deaths due to liver damage (Table 1) currently tally $18 \%$, deaths due to sepsis $6 \%$, and deaths due to associated defects now amount to $14 \%$. Mortality in the first year was $25 \%$ and later mortality was $9 \%$.

Most of the survivors ( 26 of 42 ) had no evidence of continuing liver disease and a further 13 patients had only slightly abnormal liver function. Only one of the patients who had definite liver disease at the time of review had been considered free of persisting liver disease when examined during the intervening years. Consequently, return of liver size and of biochemical test results to normal may be regarded as strong indicators of good prognosis of the liver disease.

The mortality rate (early and late) was high in familial neonatal hepatitis (six of nine) and in patients with associated second diseases without family history of neonatal liver disease (eight of 16). Those with associated second diseases (Table 1) naturally had continuing problems as part of those diseases. The liver disease healed in most of these patients. Only 12 patients, however, with idiopathic neonatal hepatitis had a completely normal liver and no disabilities (Table 2).

\begin{abstract}
Alpha $_{1}$ antitrypsin deficiency. This was associated with early death or progression to chronic liver disease in three of the nine babies (Table 1). This figure is not appreciably different from the outcome in sporadic idiopathic neonatal hepatitis (15 of 64 babies) but a trend still exists towards a slightly higher frequency of chronic liver disease in patients with neonatal hepatitis associated with $\alpha_{1}$ antitrypsin deficiency $(33 v 23 \%)$. Two children had no evidence of persisting liver disease and four showed an abnormality in just one of the number of liver function tests we used.
\end{abstract}

\section{Discussion}

The present study has followed our patients with neonatal liver disease to an average of 12 years and confirms the trends of our earlier studies. ${ }^{15}$ The loss of 11 patients to follow up has no effect on statements about the first year of life, but may bias unfavourably some of the findings about the later prognosis of the 95 patients who survived the first year. The available data suggest that this bias is not great.

Cytomegalovirus hepatitis is a very benign condition as far as the liver is concerned, but the virus may have severe effects on the brain. The high early fatality rate in babies with other infective causes of hepatitis certainly reflects a bias towards identifying acute liver damage when it is fatal; a mild case might be treated as 'sepsis', might recover, and never undergo liver biopsy. The comparatively better late outcome in this group was expected. Patients with familial neonatal hepatitis have a worse prognosis than sporadic cases, ${ }^{1-3} 518$ especially with regard to death from liver failure.

Alpha $_{1}$ antitrypsin deficiency has been claimed to be another disease with a poor prognosis among patients with neonatal liver disease. ${ }^{2} 711121920$ An association with the development of cirrhosis and a paucity of interlobular bile ducts has been noted $^{11}{ }^{21}$ but could not be identified by other authors $^{19}$ or by our analysis. This study shows a better outcome of patients with neonatal liver disease associated with $\alpha_{1}$ antitrypsin deficiency than other studies, ${ }^{2711} 121920$ with a prognosis comparable to that of sporadic cases of idiopathic neonatal hepatitis. The trend towards a slightly worse prognosis of neonatal liver disease in $\alpha_{1}$ antitrypsir deficiency should be confirmed prospectively in larger numbers of patients. It is possible that patients with a 'normal' or 'slightly abnormal liver' will go on to develop liver damage, but it seems unlikely. None of the $\alpha_{1}$ antitrypsin deficient patients who were free of symptoms of liver disease at the time of our earlier report ${ }^{1}$ has subsequently developed any signs of liver disease.

In general, babies with neonatal hepatitis of unknown aetiology and with no family history of the condition seem to die within the first few months or the liver disease seems to heal. One patient with definite liver disease at the time of review had previously been regarded as being free from liver disease. This patient illustrates the limited value of clinical examination and biochemical tests of liver function for follow up of patients with idiopathic neonatal hepatitis, but represents only slightly more than $1 \%$ of patients. In all other patients dying from liver disease the unfavourable prognosis could have been predicted by a long period of jaundice with acholic stools $^{15}$ and by the continuous disease process without apparent recovery. We expect therefore that deaths due to liver damage (with or without septicaemia) may rise to a maximum of $29 \%$, and mortality after the first year of life may rise to $17 \%$. Unfortunately, second associated diseases are frequent ${ }^{156}$ among patients with idiopathic neonatal hepatitis. These second diseases 
have caused mental and physical disabilities in a number of patients in whom the liver healed well.

It is difficult to speculate on the causes of idiopathic neonatal hepatitis, but patterns of outcome may be of some value when considering aetiology in conditions of unknown cause. The results reported here (that is mortality rates, pattern of extrahepatic defects) may be consistent with a hypothesis that most idiopathic neonatal hepatitis is caused by intrauterine infection with one of a variety of viruses (yet to be identified), that familial cases have a genetic predisposition that interferes with healing of the liver damage, and that $\alpha_{1}$ antitrypsin deficiency is one of these predisposing genotypes. ${ }^{6-10} 22$ Distinct second diseases (Table 1) may interact by rendering subclinical hepatitis clinically apparent rather than by predisposing to chronic liver disease. Knowledge of prognosis is also important when designing treatment trials. The prognosis of babies with idiopathic neonatal hepatitis who do not have prolonged jaundice and acholic stools is so good that mortality could not be used as an end point in a treatment trial. It would be necessary to choose the group of patients with persistent jaundice for any such trial.

Finally, our data indicate that most babies with neonatal hepatitis who make a complete recovery from all physical and biochemical evidence of liver disease are very likely to remain healthy and well for a long time (as far as liver disease is concerned) and probably will enter adult life with no residual effects upon the liver.

We thank all the paediatricians who allowed us to review their patients or have provided us with follow up information, and those who consistently referred patients to us and tolerated our desire to maintain a longitudinal study. Many laboratory staff contributed to the biochemical and microbiological assessments of these patients.

\section{References}

1 Danks DM. Campbell PE, Smith AL, Rogers J. Prognosis of babies with neonatal hepatitis. Arch Dis Child 1977;52:368-72.

2 Odièvre $M$, Hadchouel $M$, Landrieu $P$, Alagille $D$, Eliot $N$. Long-term prognosis for infants with intrahepatic cholestasis and patent extrahepatic biliary tract. Arch Dis Child 1981;56: 373-6.

${ }^{3}$ Henriksen NT, Drablos PA, Aagenaes O. Cholestatic jaundice in infancy. The importance of familial and genetic factors in aetiology and prognosis. Arch Dis Child 1981;56:622-7.

${ }^{4}$ Psacharopoulos HT, Mowat AP, Portmann BT, Williams R. Epidemiological study of hepatitis syndrome in infancy in Southeast England: incidence and early course. In: M Kasai, $\mathrm{K}$ Shiraki, eds. Cholestasis in infancy. Its pathogenesis, diagnosis and treatment. Tokyo/Baltimore: University Park Press, 1980:11-7.
5 Smith AL, Danks DM, Campbell PE, Rogers JG. The prognosis of babies with neonatal hepatitis. In: $M$ Kasai, K Shiraki, eds. Cholestasis in infancy. Its pathogenesis, diagnosis and treatment. Tokyo/Baltimore: University Park Press, 1980:317-23.

6 Danks DM, Campbell PE, Jack I, Rogers J, Smith AL. Studies of the actiology of neonatal hepatitis and biliary atresia. Arch Dis Child 1977;52:360-7.

${ }^{7}$ Howard ER, Mowat AP. Hepatobiliary disorders in infancy: hepatitis; extra-hepatic biliary atresia; intrahepatic biliary hypoplasia. In: HC Thomas, RNM MacSween, eds. Recent advances in hepatology 1. Edinburgh: Churchill Livingstone, 1983:153-70.

${ }^{8}$ Lieberman J, Mittman C, Gordon HW. Alpha 1 -antitrypsin in the livers of patients with emphysema. Science 1972;175:63-5.

${ }^{9}$ Aagenaes $\varnothing$. Matlary A, Elgjo K, Munthe E, Fagerhol M. Neonatal cholestasis in alpha ${ }_{1}$-antitrypsin deficient children. Acta Paediatr Scand 1972;61:632-42.

10 Porter CA, Mowat AP. Cook PJL, Haynes DWG, Shilkin KB, Williams R. Alpha ${ }_{1}$-antitrypsin deficiency and neonatal hepatitis. Br Med J 1972;iii:435-9.

$"$ Moroz SP, Cutz E, Cox DW, Sass-Kortsak A. Liver disease associated with alpha,-antitrypsin deficiency in childhood. J Pediatr 1976;88:19-25.

12 Psacharopoulos HT, Mowat AP, Cook PJL, Rodeck C. Familial factors and the severity of liver disease in genetic deficiency of alpha ${ }_{1}$-antitrypsin (PiZZ). Arch Dis Child 1981;56:803-4.

13 Sveger T. Prospective study of children with alpha ${ }_{1}$-antitrypsin deficiency: eight-year-old follow-up. J Pediatr 1984;104:91-4.

14 Sackett DL, Whelan G. Cancer risk in ulcerative colitis: scientific requirements for the study of prognosis. Gastroenterology 1980;78:1632-5.

15 Watson GH, Miller V. Arteriohepatic dysplasia. Familial pulmonary arterial stenosis with neonatal liver disease. Arch Dis Child 1973;48:459-66.

16 Alagille D, Odièvre M, Gautier M, Dommergues JP. Hepatic ductular hypoplasia associated with characteristic facies, vertebral malformations, retarded physical, mental, and sexual development, and cardiac murmur. J Pediatr 1975;86:63-71.

${ }_{17}$ Mashige F, Imai K, Osuga T. A simple and sensitive assay of total serum bile acids. Clin Chim Acta 1976;70:79-86.

${ }^{18}$ Lawson EE, Boggs JD. Long-term follow-up of neonatal hepatitis: safety and value of surgical exploration. Pediatrics 1974;53:650-5.

${ }^{19}$ Psacharopoulos HT, Mowat AP, Portmann BT, Williams R. The prognosis in childhood of liver disease associated with alpha $_{1}$-antitrypsin deficiency (PiZZ). In: M Kasai, K Shiraki, eds. Cholestasis in infancy. Its pathogenesis, diagnosis and treatment. Tokyo/Balitmore: University Park Press, 1980: 133-40.

20) Cox DW. Alpha,-antitrypsin deficiency. In: MM Fisher, CC Roy, eds. Pediatric liver disease. New York: Plenum Press, 1983:271-82.

21 Alagille D. Alpha ${ }_{1}$-antitrypsin deficiency. Hepatology $1 \overline{98} \overline{4}$; 4:11S-4S.

${ }^{22}$ Nebbia G, Hadchouel M, Odièvre M, Alagille D. Early assessment of evolution of liver disease associated with alpha $a_{1}$ antitrypsin deficiency in childhood. J Pediatr 1983;102:661-4.

Correspondence to $\mathrm{Dr} \mathrm{J}$ Deutsch. Universitäts-Kinderklinik, Auenbruggerplatz, A-8036 Graz/Austria.

Received 10 January 1985 